\title{
A State-Space Model and Control of a Full-Range PMSG Wind Turbine for Real-Time Simulations
}

\author{
Agustín Tobías-González $^{1}$. Rafael Peña-Gallardo ${ }^{1} \cdot$ Jorge Morales-Saldaña $^{1}$. \\ Aurelio Medina-Ríos ${ }^{2}$. Olimpo Anaya-Lara ${ }^{3}$
}

Received: 10/11/2017 / Accepted:

\begin{abstract}
Direct drive permanent magnet synchronous generators (PMSG) have drawn great interest to wind turbine manufacturers, due to the advance of power electronic technology, improved designs and fabrication procedures of these types of generators. In this research, a state-space model of a PMSG wind turbine was developed, and used for the obtainment of a control strategy in a easier way for a test system in the $d q$ reference frame. Then, a complete model of a PMSG wind turbine connected to an electric grid through a fullscale Back-to-Back (BTB) converter with its controls was implemented, using the detailed models included in a RealTime Digital Simulator (RTDS). Simulation results show that the controllers perform efficiently during transient and steady state conditions, and that the presented model can be used for the development of control strategies prior to their implementation in a professional software.
\end{abstract}

Keywords Control Strategies · Modeling and Simulation · Real Time · Synchronous Generator · Variable Speed Wind Turbine.

\section{Introduction}

Wind power is today's most rapidly growing renewable energy source. Wind turbines can either operate at fixed speed or

\section{$凶$ Rafael Peña-Gallardo}

rafael.pena@uaslp.mx

${ }^{1}$ Facultad de Ingeniería, Universidad Autónoma de San Luis Potosí, San Luis Potosí, México

${ }^{2}$ Facultad de Ingeniería Eléctrica, Universidad Michoacana de San Nicolás de Hidalgo, Morelia, México

${ }^{3}$ Institute for Energy and Environment, University of Strathclyde, Glasgow, UK variable speed. In a fixed-speed wind turbine, the generator, normally a conventional squirrel-cage induction machine is directly connected to the grid through a transformer [1-3]. Variable speed wind turbines are controlled by power electronic equipment, and depending on the arrangement, both induction and synchronous machines can be employed [47].

Recently, the concept of a variable-speed wind turbine equipped with permanent magnet synchronous generators (PMSG) has received increased attention by various wind turbine manufacturers. The use of permanent magnets in the rotor of the PMSG makes unnecessary to supply magnetizing current through the stator for constant air-gap flux; the stator current needs to be only torque producing $[8,9]$. Hence for the same output, the PMSG can operate at a higher power factor because of the absence of magnetizing current, and will be more efficient than the induction machine used in other types of wind turbines.

Several models that represent the dynamic behavior of the PMSG wind turbine have been reported in the open literature. Most of them are formulated in the phase domain [10], since in this frame the dynamics of the PMSG wind turbine can be represented in a natural way. For instance, recently in [11] a dynamic model of a PSMG wind turbine is proposed for small capacity turbines, while in [12] the dynamic modeling and control of a PMSG wind turbine with MPPT control connected to the grid is presented. However, phase domain models have the disadvantage that the computational load involved in their solution is high, and because of this, they are not suitable for real-time simulations [13].

To overcome this problem, models in the $d q$ reference frame have been developed; these models consider the most suitable scheme of the test system according to the topology under study and the control necessities $[1,6,14]$. In the case of real-time simulations the complexity of the model and the computational effort are two aspects to take into account in 
the modeling $[4,15]$. In this contribution a state-space model in the $d q$ reference frame was developed based on these considerations, that is, the model needs to be simpler compared with models obtained in the phase domain and preserve the dynamic behavior of the test system. The developed model meets these characteristics and includes the modulation signal required to control the power electronic converter, that allows the link between the wind turbine and the grid; variable that is omitted in many works.

On the other hand, various techniques have been developed to investigate the behavior of a PMSG wind turbine under different $d q$ control conditions [16-19]. The most widely used control technique is the linear control based on the proportional integral derivative (PID) technique, since it is robust, simple and easy to implement [20]. Nonlinear control has been also used for the control of wind turbines; the most popular technique is the sliding mode control [21]. This technique has the advantage to be robust and provides dynamic invariant property with uncertainties, however this technique presents the chaterring phenomenon [22]. Alternative control techniques based on intelligent algorithms also have been proposed for the control of wind turbines, such as neural networks [23,24], and fuzzy control [25]. Another type of control reported in the literature is the predictive control; this technique is used to represent the behavior of complex dynamic systems using estimation models [26].

Regarding to the control strategy developed in this contribution, a linear control strategy was used for the PSMG wind turbine, because the computational effort is low, it can be used for real-time simulations and performs well under different scenarios.

The state-space model of a PMSG wind turbine presented in this paper includes a full-scale BTB converter for its connection with an electric grid, for the study and obtainment of a full-control strategy. The implementation of the model was done in the $\mathrm{C}$ programming language, the model was designed to be included as part of the main component library of the graphical user interface of a Real-Time Digital Simulator (RTDS) [27]. This model can be connected to other customized component model libraries included in the RSCAD software. The controllers were programmed in a digital device, using the Rapid Control Prototyping (RCP) technique [28], with the aim to explore the system performance in real-time $[29,30]$.

The rest of this paper is organized as follows: Section 2 presents a description of the structure and the modeling of the test system; Section 3 presents the PMSG wind turbine model developed in this research; Section 4 shows control strategies used in the converter in order to obtain the maximum power extraction of the wind turbine; Section 5 contains the tuning technique used in the controllers; Section 6 describes the RTDS station used in this investigation, as well as some considerations taken into account at the moment of the implementation of the wind turbine model and the control strategy using the RCP technique; in Section 7 simulations of the PMSG wind turbine model connected to an electric grid through a electronic converter during transient conditions are presented and discussed; finally, Section 8 draws the main conclusions of this work.

\section{Structure and modeling of the test system}

Fig. 1 illustrates the general structure of a PMSG wind turbine connected to grid. The system consists of the following elements [31,32]:

a) A wind turbine including a stochastic model that represents a wind sequence.

b) A standard permanent magnet synchronous machine, with the stator windings connected to the grid through a fullscale frequency converter.

c) A model of a grid.

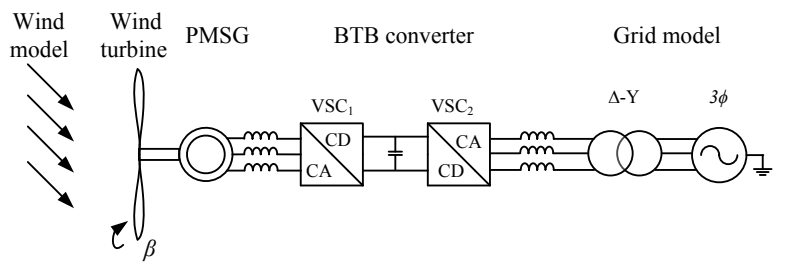

Fig. 1 PMSG wind turbine.

\subsection{Wind model}

This model represents the behavior of the wind as a speed sequence, and it has the advantage of cover a full range of characteristics of a real wind sequence. The model is composed by the sum of four components [33]:

$v_{w}(t)=v_{a v g}+v_{r}(t)+v_{g}(t)+v_{t}(t)$,

where $v_{\text {avg }}$ is the average value of the wind speed $(\mathrm{m} / \mathrm{s})$, $v_{r}(t)$ is the ramp component $(\mathrm{m} / \mathrm{s}), v_{g}(t)$ is the gust component $(\mathrm{m} / \mathrm{s})$, and $v_{t}(t)$ is the turbulence component of the wind $(\mathrm{m} / \mathrm{s})$, which is defined by Eq. (2) [33].

$v_{t}(t)=\sum_{i=1}^{n} \sqrt{S_{w t}\left(f_{i}\right) \Delta f} \cos \left(2 \pi f_{i} t+\phi_{i}+\Delta \phi\right)$

Where $f_{i}$ is the frequency of $i-t h$ component $(\mathrm{Hz}), \phi_{i}$ is the phase of the same component ( $\mathrm{rad}), h$ is the height to the shaft level $(\mathrm{m}), l$ is the turbulence length $(\mathrm{m})$, and $z_{0}$ is the roughness length and it depends of the landscape (m). 
$S_{w t}\left(f_{i}\right)$ is the power spectrum $(\mathrm{W} / \mathrm{Hz})$, given by the Eq. (3), established in the Danish standard[34].

$S_{w t}\left(f_{i}\right)=\frac{\frac{1}{\left(\ln \left(h / z_{0}\right)\right)^{2}} l v_{\text {avg }}}{\left(1+1.5 \frac{f_{i} l}{v_{\text {avg }}}\right)^{\frac{5}{3}}}$

\subsection{Aerodynamic model}

There are many mathematical models that have been obtained to describe the relationship between the wind speed and the mechanical power extracted from the wind $[35,36]$. This paper uses the following equation to model a wind turbine:

$P_{w}=\frac{\rho}{2} A_{r} C_{P}(\lambda, \beta) v_{w}{ }^{3}$

where $P_{w}$ is the extracted power from the wind, $\rho$ is the air density $\left(\mathrm{kg} / \mathrm{m}^{3}\right), A_{r}$ is the area covered by the wind turbine rotor $\left(\mathrm{m}^{2}\right), v_{w}$ is the wind speed $(\mathrm{m} / \mathrm{s})$, and $C_{p}$ is the power coefficient which is a function of both tip speed ratio $\lambda$, and blade pitch angle $\beta$ (rad). To calculate $C_{p}$ for the given values of $\beta$ and $\lambda$ the following numerical approximation has been used [37].

$C_{P}(\lambda, \beta)=c_{1}\left(\frac{c_{2}}{\lambda_{i}}-c_{3} \beta-c_{4}\right) e^{\left(-\frac{c_{5}}{\lambda_{i}}\right)}+c_{6} \lambda$

$\lambda_{i}=\left[\left(\frac{1}{\lambda+0.08 \beta}\right)-\left(\frac{0.035}{\beta^{3}+1}\right)\right]^{-1}$

The values of the coefficients $c_{1}-c_{6}$ are dependent of the wind turbine design. In this research the following values were used: $c_{1}=0.5176, c_{2}=116, c_{3}=0.4, c_{4}=5, c_{5}=21$ and $c_{6}=0.0068$. Fig. 2 shows curves of $C_{p}$ for different wind speed values. Each curve shows a maximum point that corresponds to the maximum power that can be extracted from the wind.

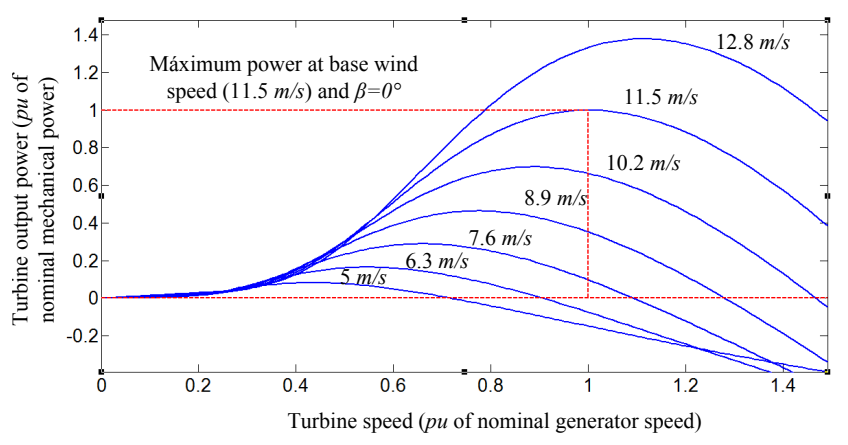

Fig. 2 Wind turbine power characteristics with $\beta=0^{\circ}$.

\subsection{Torque equation}

The torque equation describing the mechanical behavior of the wind turbine can be written based on a single-mass model given as $[33,38]$ :

$T_{e}=\frac{2 J}{P} \frac{d}{d t} \omega_{r}+\frac{2 B_{m}}{P} \omega_{r}+T_{L}$

where $T_{L}$ is the average aerodynamic torque $(\mathrm{N} \cdot \mathrm{m}), T_{e}$ is the electromagnetic torque $(\mathrm{N} \cdot \mathrm{m}), J$ is the inertia constant of the wind turbine and the generator $\left(\mathrm{kg} \cdot \mathrm{m}^{2}\right), \omega_{r}$ is the frequency of the generator rotor $(\mathrm{rad} / \mathrm{s}), P$ is the number of poles of the machine, and $B_{m}$ is a damping coefficient associated with the rotational system of the machine and the mechanical load $(\mathrm{N} \cdot \mathrm{m} \cdot \mathrm{s})$.

\subsection{Generator model}

The generator was modeled considering the following assumptions:

- Magnetic saturation is neglected.

- Any losses, apart from copper losses, are neglected.

- The flux distribution in the windings is considered to be perfectly sinusoidal.

The voltage equations of a permanent magnet synchronous generator in the $d q$ synchronous reference frame can be expressed as [38]:

$v_{s}^{d r}=R_{s} i_{s}^{d r}+L_{d} \frac{d}{d t} i_{s}^{d r}+\omega_{r} L_{q} i_{s}^{q r}+\omega_{r} \lambda_{m}^{\prime r}$

$v_{s}^{q r}=R_{s} i_{s}^{q r}+L_{q} \frac{d}{d t} i_{s}^{q r}-\omega_{r} L_{d} i_{s}^{d r}$

where $v_{s}^{d, q}$ are the voltages $(\mathrm{V}), R_{s}$ is the resistance $(\Omega)$, $i_{s}^{d, q}$ are the currents (A), $L_{d, q}$ are the inductances of the stator $(\mathrm{H})$, and $\lambda_{m}^{\prime r}$ is the flux of the permanent magnet $(\mathrm{Wb})$. The $s$ subscript denotes variables and parameters associated with the stator circuit and $r$ subscript is associated with rotor variables; the $d q$ superscript stands for variables in the synchronous reference frame.

The electromagnetic torque $T_{e}$ developed by the machine $(\mathrm{N} \cdot \mathrm{m})$ can be obtained from the following equation [39]:

$T_{e}=\frac{3 P}{4}\left[\lambda_{m}^{\prime r} i_{s}^{d r}+\left(L_{q}-L_{d}\right) i_{s}^{d r} i_{s}^{q r}\right]$

\subsection{Full-scale BTB converter model}

The configuration of a PMSG wind turbine requires a fullscale frequency converter, which enables individually control the active and reactive power and a smoother connection to the grid [33], also contributes to a well-proven robust and reliable performance [9]. 
Fig. 3 shows a PMSG wind turbine with a two-level fullscale BTB converter selected for the connection of the wind turbine to the grid. This topology gives the advantage of increasing the degrees of freedom in the system, where the $V S C_{1}$ controls the active and reactive power provided by the PMSG and the $V S C_{2}$ controls the regulation of the DC-link, and the reactive power at the Point of Common Coupling (PCC) $[40,41]$.

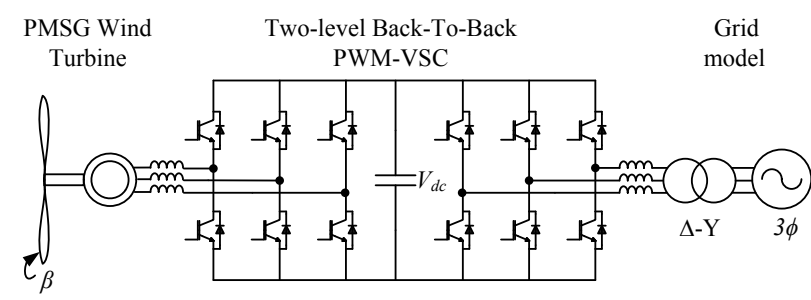

Fig. 3 BTB converter topology.

The dynamic model for the BTB converter [40] is obtained in order to have a full dynamic model of the system, and design the control strategies.

\section{Full dynamic model of a PMSG wind turbine including a BTB converter}

Taking into account the Eqs. (7)-(10) and the model of the BTB converter shown in the Fig. 3 [40], a state-space model of the PMSG wind turbine was obtained.

Equations (11)-(16) show the state-space dynamic model for the PMSG wind turbine including a BTB converter developed in this research. This model is helpful for the design and analysis of different control strategies; besides, it represents the dynamic behavior of the complete system and can be used in different type of studies.

$\frac{d}{d t} \omega_{r}=-\frac{B_{m}}{J} \omega_{r}+\frac{3 P^{2} \lambda_{m}^{\prime}}{8 J} i_{1}^{d}-\frac{P}{2 J} T_{L}$

$\frac{d}{d t} i_{1}^{d}=\left[\frac{1}{L_{1}-L_{d}}\right]\left[\left(R_{s}-R_{1}\right) i_{1}^{d}+\left(L_{1}+L_{q}\right) \omega_{r} i_{1}^{q}+\lambda_{m}^{\prime} \omega_{r}-\frac{m_{1}^{d} v_{c d}}{2 U_{T 1}}\right]$

$\frac{d}{d t} i_{1}^{q}=\left[\frac{1}{L_{1}-L_{q}}\right]\left[\left(R_{s}-R_{1}\right) i_{1}^{q}-\left(L_{1}+L_{d}\right) \omega_{r} i_{1}^{d}-\frac{m_{1}^{q} v_{c d}}{2 U_{T 1}}\right]$

$\frac{d}{d t} i_{2}^{d}=-\frac{R_{2}}{L_{2}} i_{2}^{d}+\omega_{2} i_{2}^{q}+\frac{v_{2}^{d}}{L_{2}}-\frac{m_{2}^{d} v_{c d}}{2 U_{T 2} L_{2}}$

$\frac{d}{d t} i_{2}^{q}=-\frac{R_{2}}{L_{2}} i_{2}^{q}-\omega_{2} i_{2}^{d}+\frac{v_{2}^{q}}{L_{2}}-\frac{m_{2}^{q} v_{c d}}{2 U_{T 2} L_{2}}$

$\frac{d}{d t} v_{c d}=\frac{3}{2 C_{c d} U_{T 1}}\left(m_{1}^{d} i_{1}^{d}+m_{1}^{q} i_{1}^{q}\right)+\frac{3}{2 C_{c d} U_{T 2}}\left(m_{2}^{d} i_{2}^{d}+m_{2}^{q} i_{2}^{q}\right)$

Eq. (11) represents the shaft model including the electromagnetic torque; Eq. (12) and (13) represent the $V S C_{1}$; Eq. (14) and (15) represent the $V S C_{2}$; and Eq. (16) represents the dynamic of the DC-link voltage. Besides, $v_{i}^{d}$ and $v_{i}^{q}$ are the voltages, $i_{i}^{d, q}$ the line currents, $R_{i}$ and $L_{i}$ are the resistance and the inductance of the $V S C_{i}$, respectively, $v_{d c}$ the voltage in the DC-link, $m_{i}^{d, q}$ is the signal of modulation and $U_{T i}$ the maximum value of the triangular wave for the Pulse-Width Modulation (PWM).

It is important to mention that this developed model is used to obtain the control techniques for the wind system, then these techniques were tested using the detailed models included in RSCAD and the results show that they work well and were obtained using a simplified model in an easier way.

\section{Control strategies of the BTB converter}

The design of the control strategies considers the operation of the variable speed wind turbine within three regions, which allow an optimal power extraction on a wide range of wind values, with a safe and optimal operation for the system.

Fig. 4 describes three basic operating regions of a variable speed wind turbine [42], where the region $\mathrm{A}$ is the operation on a low wind speed profile (LWS). In this region the value of the wind speed is below the rated value and it is necessary to operate the wind turbine at an optimal speed, trying to extract the maximum power from the wind (see Fig. 2). This is achieved by keeping the tip speed ratio at an optimal value, that is, $\lambda=\lambda_{\text {opt }}$, and the pitch angle at a minimum constant value of $\beta=\beta_{0}$. The region $\mathrm{B}$ is the transition region between region $\mathrm{A}$ and $\mathrm{C}$, where the system must have a smooth operation in order to avoid sudden mechanical vibrations that can damage the turbine. The operation of the wind turbine in a wind speed above of the rated value or at high wind speeds (HWS) is carried out in the region $\mathrm{C}$, where the mechanical speed must not exceed the design value of the wind turbine $\omega_{m}=\omega_{\text {nom }}$, and also it has to deliver its nominal electrical power to the network; this is achieved using the pitch angle control.

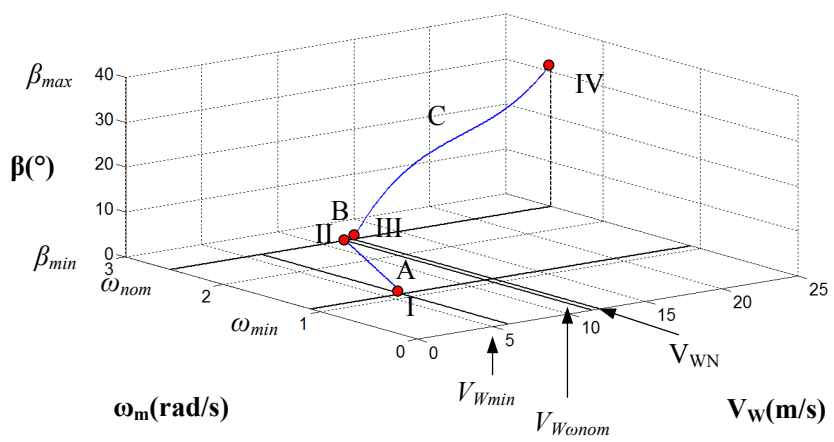

Fig. 4 Operating regions of a variable speed wind turbine.

For the operating regions mentioned above in this research the following control objectives have been selected:

- Optimal power extraction. 
- Mitigation of mechanical loads.

- Keep the power quality.

In this paper, the direct drive PMSG concept is adopted with the utilization of fully-controlled power converters. The BTB converter assembly consists of a generator side AC/DC converter, a DC-link capacitor, and a grid side DC/AC converter. Each of the two power converters is composed of a two-level PWM-VSC converter.

The design of the control strategy of the PMSG wind turbine is based on the dynamic model given by the Eqs. (11)-(16). Fig. 5 shows the control scheme that considers the operation of the wind turbine in the LWS and HWS regions, where $\omega_{\text {mppt }}$ is the optimal speed when the wind turbine operate bellow the rated wind speed, and in the HWS region prevails the operation of the pitch angle controller to maintain the shaft speed at its nominal value.

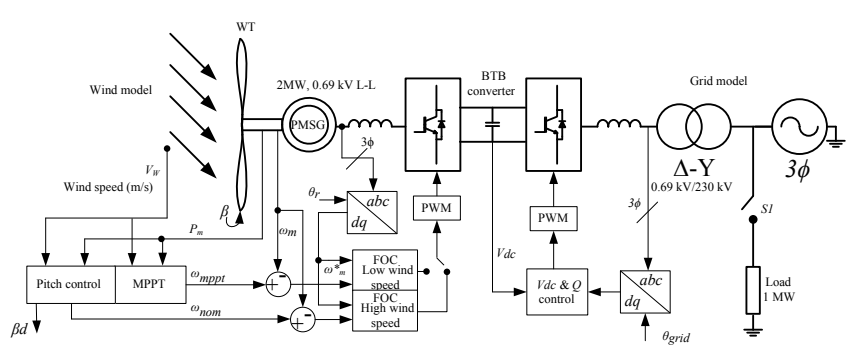

Fig. 5 Diagram of the PMSG wind turbine control [43].

\subsection{Obtaining of the MPPT reference}

The reference given for the maximum power point tracking algorithm (MPPT) is obtained from a function of the maximum points of the $C_{p}$ curves, shown in Fig. 2, and described by Eq.(17).

$\omega_{\text {mppt }}=0.0000321 v_{w}^{3}+0.0003950 v_{w}^{2}+0.2060213 v_{w}+0.076506$

Appling the $d q$ transformation in the rotating reference frame, the active and reactive power generated by the wind turbine are given by:

$P=\frac{3}{2}\left(v^{q} i^{q}+v^{d} i^{d}\right)$

$Q=\frac{3}{2}\left(v^{q} i^{d}-v^{d} i^{q}\right)$

If the reference frame is such that $v^{q}=0$ and $v^{d}=|v|$, the equations for the active and reactive power are,

$P=\frac{3}{2}\left(v^{d} i^{d}\right)$

$Q=\frac{3}{2}\left(v^{d} i^{q}\right)$
Therefore, the active and reactive powers can be controlled by means of the direct and quadrature current components, respectively.

\subsection{Generator-side converter control}

The Field Oriented Control (FOC) is used as the control technique for the converter of the generator-side. The FOC scheme proposed in this paper is shown in the Fig. 6. As this converter is directly connected to the PMSG, a mechanical speed reference given from a Maximum Power Point Algorithm (MPP) $\omega_{m p p t}$ is needed to determine the maximum power extraction from the wind.

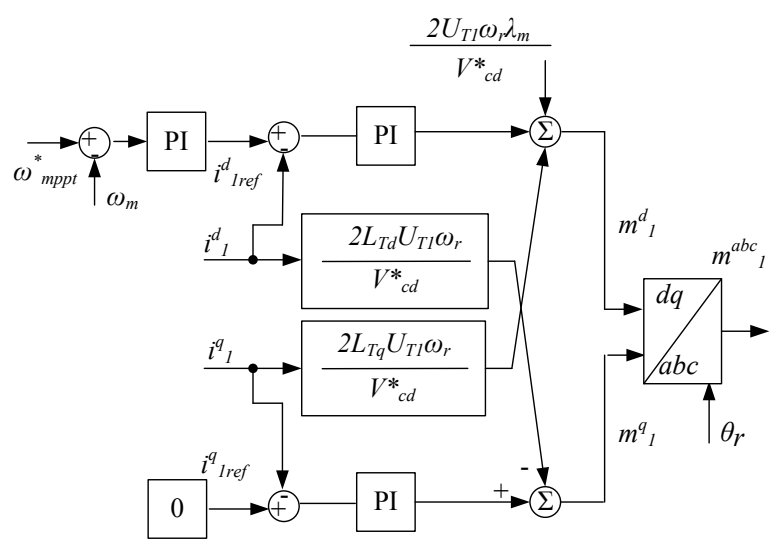

Fig. 6 Control block diagram of generator-side converter.

The active power can be controlled by means of the $i^{d}$ current, as described in Eq. (20). The angle $\theta_{r}$, for the transformation between $a b c$ and $d q$ variables is calculated from the rotor speed of the PMSG.

The Control Law for the FOC can be described by the following equations:

$$
\begin{aligned}
& m_{1}^{d}=\frac{2 U_{T 1}}{V_{d c}^{*}}\left(\left(R_{S}-R 1\right) i_{1}^{d}+L_{T d} \omega_{r} i_{1}^{q}+\omega_{r} \lambda_{m}^{\prime r}\right)-U_{11} \\
& m_{1}^{q}=\frac{2 U_{T 1}}{V_{d c}^{*}}\left(\left(R_{S}-R_{1}\right) i_{1}^{q}-L_{T q} \omega_{r} i_{1}^{d}\right)-U_{12}
\end{aligned}
$$

where $U_{11}$ and $U_{12}$ are PI controllers, and the decoupling terms are $L_{T d} \omega_{r} i_{1}^{q}$ and $L_{T q} \omega_{r} i_{1}^{d}$.

Considering the closed loop for the $i^{d}$ current, the PI control equation is:

$U_{11}=K_{p 11}\left(i_{1 r e f}^{d}-i_{1}^{d}\right)+\frac{K_{i 11}}{s}\left(i_{1 r e f}^{d}-i_{1}^{d}\right)$

and the transfer function for the closed loop is obtained by substituting Eq. (22) into Eq. (12):

$$
G_{11}(s)=\frac{i_{1}^{d}(s)}{i_{1 r e f}^{d}(s)}=\frac{V_{c d}^{*}\left(K_{p 11} s+K_{i 11}\right)}{2 U_{T 1}\left(L_{1}-L_{d}\right) s^{2}+K_{p 11} V_{c d}^{*} s+K_{i 11} V_{c d}^{*}}
$$




\subsubsection{Speed control loop}

The outer loop that sends the reference $i_{1 \text { ref }}^{d}$ is obtained from Eq. (11), where it is considered that $B_{m}=0$ and $T_{L}$ is a perturbation, resulting in the control scheme shown in Fig. 7.

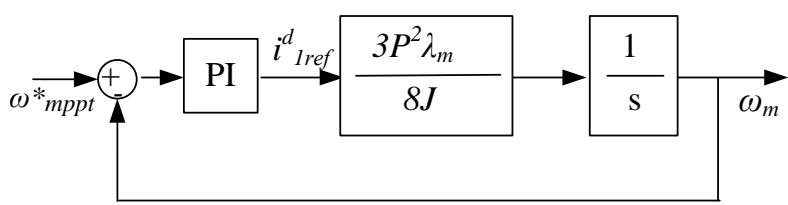

Fig. 7 Speed control.

The closed loop transfer function is:

$G_{\omega}(s)=\frac{\omega_{m}}{\omega_{m p p t}^{*}}=\frac{3 P^{2} \lambda_{m}^{\prime}\left(K_{p \omega} s+K_{i \omega}\right)}{8 J s^{2}+3 P^{2} \lambda_{m}^{\prime}\left(K_{p \omega} s+K_{i \omega}\right)}$

\subsection{Load-side converter control}

The control objectives for the load-side converter are to regulate the DC-link voltage and to control the reactive power exchange with the network. The control strategy used in the grid-side of the inverter is the Decoupled Current Control (DCC). This technique allows to have an independent control of the currents in the $d q$ synchronous reference frame.

The control law for the DCC can be described by the following equations:

$m_{2}^{d}=\frac{2 U_{T 2}}{V_{d c}^{*}}\left(L_{2} \omega_{2} i_{2}^{q}+v_{2}^{d}\right)+U_{21}$

$m_{2}^{q}=\frac{2 U_{T 2}}{V_{d c}^{*}}\left(-L_{2} \omega_{2} i_{2}^{d}+v_{2}^{q}\right)+U_{22}$

where $U_{21}$ and $U_{22}$ are PI controllers and the decoupling terms are $L_{2} \omega_{2} i_{2}^{q}$ and $L_{2} \omega_{2} i_{2}^{d}$.

Control blocks for the load-side converter with the DCC strategy are shown in Fig. 8. The control scheme consists in two inner control loops for the $d q$ currents and two outer loops that send the current reference need to meet the control objectives.

In the same way than the FOC, the closed loop transfer function in the inner control loop is obtained by substituting Eq. (27) in Eq. (14).

\subsubsection{DC-link control}

The transfer function for the outer closed loop that sends the $i_{2}^{d}$ reference is obtained by considering the steady state operation, i.e. the Eq. (16) with $\frac{d}{d t} i_{2}^{d}=0$, a unity power factor

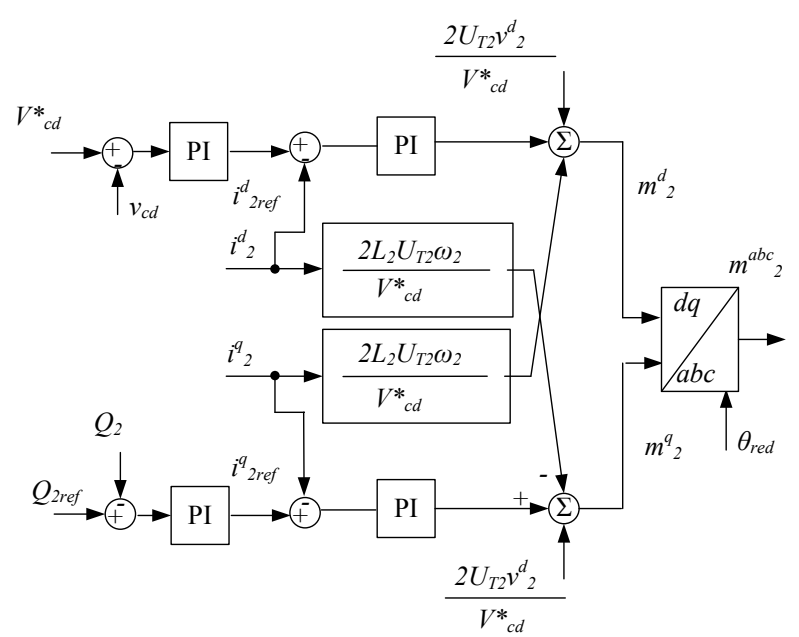

Fig. 8 Control block diagram of grid-side inverter.

with $Q_{2}=0$ and a PI controller, resulting in the following transfer function for the DC-link control:

$G_{c d}=\frac{v_{c d}(s)}{V_{c d}^{*}(s)}=\frac{v_{2}^{d}\left(K_{p_{c d}} s+K_{i_{c d}}\right)}{\frac{3}{2} V_{c d}^{*} C_{c d} s^{2}+K_{p_{c d}} v_{2}^{d} s+K_{i_{c d}} v_{2}^{d}}$

\subsubsection{Reactive power control}

The reactive power control is carried out from Eq. (21); its loop control sends the $i^{q}$ reference to both converters. The closed loop transfer function with a PI controller is given as:

$G_{Q_{i}}=\frac{Q_{i}(s)}{Q_{i}^{*}(s)}=\frac{v_{i}^{d}\left(K_{p_{i 1}} s+K_{i_{i 2}}\right)}{\left(\frac{2}{3}-K_{p_{i 1}} v_{i}^{d}\right) s-K_{i_{i 2}} v_{1}^{d}}$

\subsection{High wind speed control}

Control objectives in the HWS region are to limit the mechanical speed when the wind speed exceeds its nominal value $v_{w_{n o m}}$, and to send the nominal power to the grid. These objectives are met by using a pitch angle controller that takes into account the mechanical power limit of the wind turbine, the nominal speed of the mechanical system, and the pitch angle required to maintain these parameters within limits.

The control scheme for this purpose is shown in the Fig. 9, which has two control loops, one for the nominal speed and other for the nominal mechanical power, it also has a time constant $\tau$ of the pitch actuator.

The transfer function for the pitch angle control is given as:

$G_{\beta}(s)=\frac{\left(K_{p_{\beta}}+K_{p p}\right) \tau s^{2}+\left(K_{i_{\beta}} \tau+K_{p_{\beta}}\left(K_{p p}+1\right)+K_{p p}\left(K_{p_{\beta}}+1\right)\right) s+2 K_{i_{\beta}} K_{p p}+K_{i_{\beta}}}{\tau^{2} s^{3}+\left(\tau+\tau\left(\mathrm{K}_{\mathrm{p}_{\beta}}+1\right)\right) s^{2}+\left(\mathrm{K}_{\mathrm{p}_{\beta}}+\mathrm{K}_{\mathrm{i}_{\beta}} \tau+1\right) s+\mathrm{K}_{\mathrm{i}_{\beta}}}$ 


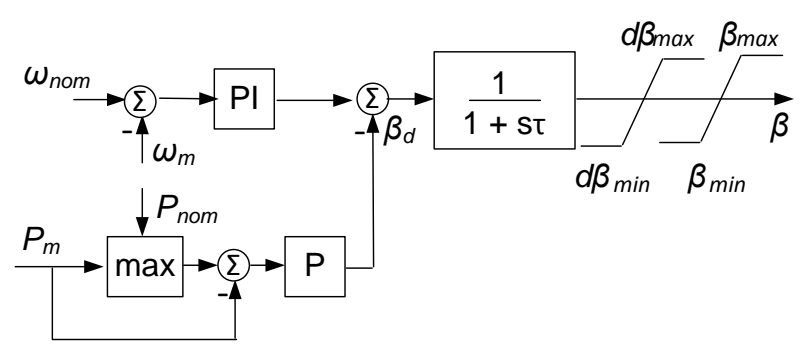

Fig. 9 Control scheme for the pitch angle.

\section{Tuning control loops}

Since the control strategies for the BTB converter contain cascade control loops, for tuning a inner control loop, it is necessary to select a bandwidth below of the switching frequency. For instance the criteria used on [44] is a frequency ratio of $z_{T}=\frac{f_{s w_{i}}}{f_{i}} \geq 9$.

\subsection{Tuning cascade loops of FOC}

The switching frequency for the converter at the generatorside is selected with a modulation index $m_{f}=81$ for $f_{1}=$ $24.54 \mathrm{~Hz}$, resulting in $f_{s w 1}=1,987 \mathrm{~Hz}$. The inner loops are tuned first setting the proportional gain with a value of $k_{p_{11}}=0.009$ and for a bandwidth required, with the integral gain selected as $k_{i_{11}}=0.0001$, where its frequency ratio is $z_{T}=13$. On the other hand, the proportional and integral gains for the bandwidth of the outer speed loop are selected by using a second order system:

$s^{2}+2 \zeta \omega_{n} s+\omega_{n}^{2}$

and considering $\omega_{n}=2.57 \mathrm{rad} / \mathrm{s}$ and $\zeta=0.59$ for an percentage overshoot $P O=10 \%$, the result is:

$K_{p \omega}=\frac{16 J \zeta \omega_{n}}{3 P^{2} \lambda_{m}^{\prime}}=4.66$

$K_{i \omega}=\frac{8 J \omega_{n}^{2}}{3 P^{2} \lambda_{m}^{\prime}}=10.139$

The closed loop frequency response is shown in the bode diagram of the Fig. 10 with $z_{T}=63$.

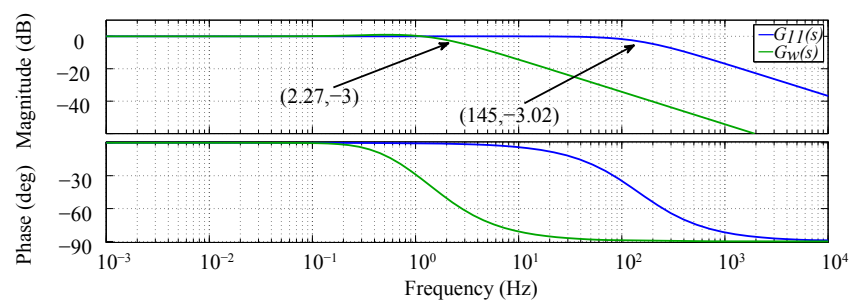

Fig. 10 Frequency response of cascade loops in the FOC.

\subsection{Tuning cascade loops of DCC}

The cascade loops of DCC are tuned in the same way that the FOC, with $f_{2}=60 \mathrm{~Hz}$ and $f_{s w_{2}}=4,860 \mathrm{~Hz}$, resulting in the following gains for the inner loops and the DC-link, respectively: $k_{p_{21}}=0.0018$ and $K_{i_{21}}=0.0003 ; K_{p_{c d}}=2.0$ and $K_{i_{c d}}=9.0$. The frequency response is shown in Fig. 11.

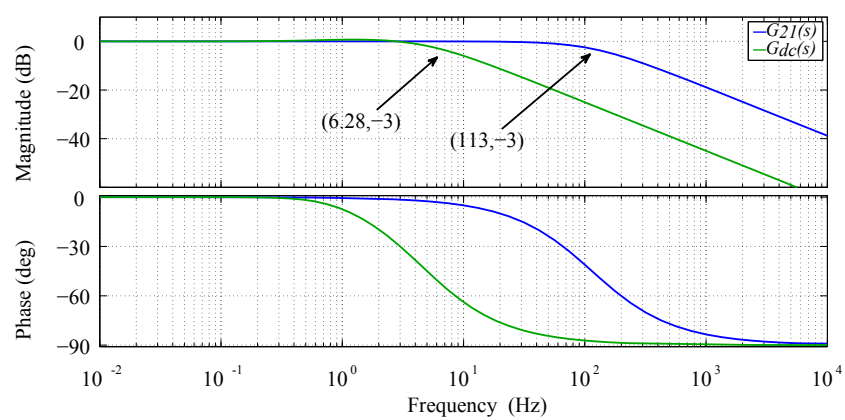

Fig. 11 Frequency response of the cascade loops of the DC-link and the inner current loop.

\subsubsection{Tuning the reactive power loop}

The reactive power loop considers tuning the PI controller with the grid frequency, and the bandwidth with a value of a decade away from the previous inner loop; this is achieved with the following expression:

$K_{i_{Q}}=\frac{\omega_{c}}{3 v_{2}^{d}} \sqrt{\frac{10^{-\frac{3}{10}}\left(-3 K_{p_{Q}} v_{2}^{d}+2\right)^{2}-\left(3 K_{p_{Q}} v_{2}^{d}\right)^{2}}{1-10^{-\frac{3}{10}}}}$

Considering $\omega_{c}=377 \mathrm{rad} / \mathrm{s}, K_{p_{Q}}=0.0001$, and the negative sign for the Routh-Hurwitz criteria resulting in $K_{i_{Q}}=$ -0.4059 , the frequency response for the reactive power loop of the DCC is shown in Fig. 12.

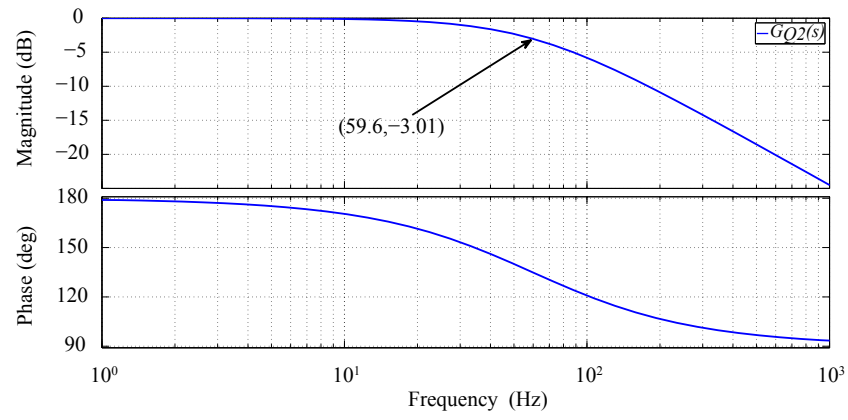

Fig. 12 Frequency response of the reactive power loop. 


\subsection{Tuning the pitch angle control loop}

This loop takes into count an arbitrary time constant of the actuator of the blades $\tau=2.5 \mathrm{~s}$. By using the principle of superposition, the upper loop is tuned in a decade below from the speed loop with $K_{p_{\beta}}=5.0$ and $K_{i_{\beta}}=0.003$, then the lower loop sets the gain of the closed loop to an unit gain with the proportional gain of the controller of $K_{p p}=0.2$, resulting in the frequency shown in Fig. 13.

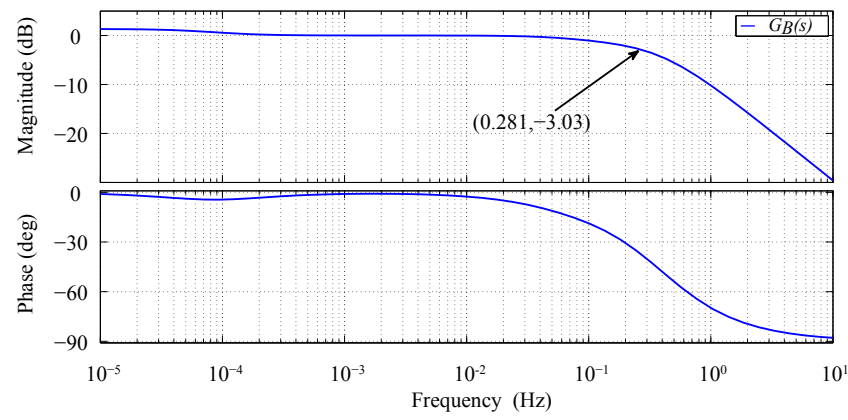

Fig. 13 Frequency response of the pitch control loop.

\subsection{HWS operation}

The proposed tuning of controllers in the LWS region may have an oscillatory response when the wind turbine operates in the HWS region. To overcome this possible problem, the proportional gains of the inner loops in the FOC are set to $K_{p_{11} h}=K_{p_{12} h}=0.0045$. The frequency response for these gains are shown in the bode diagram of Fig. 14.

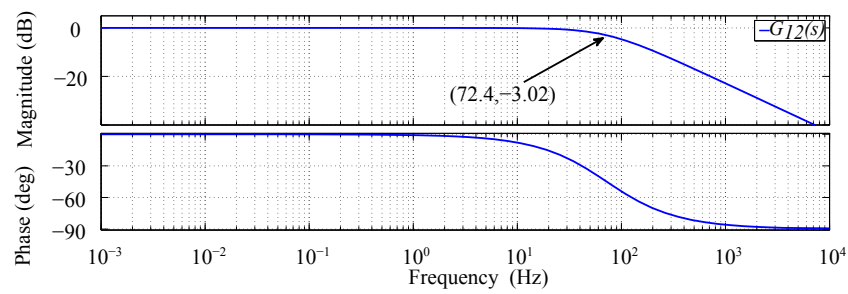

Fig. 14 Frequency response inner loops of FOC in HWS region.

Fig. 15 shows the switching scheme for the proportional gains of the inner loops of the FOC in both regions.

\section{Real-time implementation}

The Real Time Digital Simulator (RTDS) is a combination of specialized computer hardware and software designed specifically for the solution of power system electromagnetic transients. This solution is carried-out in real-time, that is, the RTDS station can solve power system equations fast

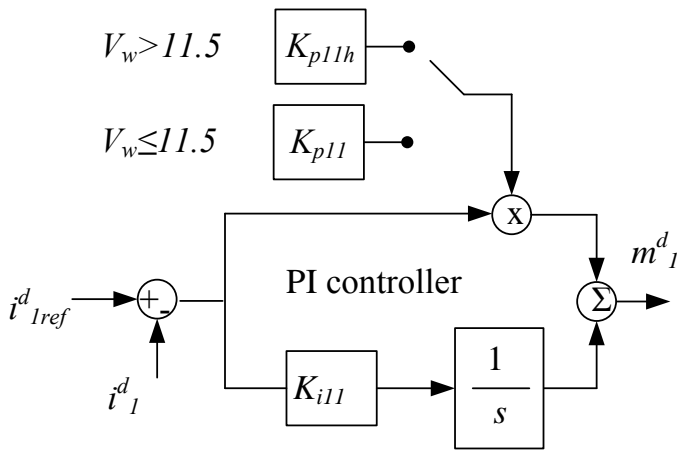

Fig. 15 Gains in the LWS and the HWS regions.

enough to continuously produce output conditions that realistically represent operation conditions in real power systems [45].

The RTDS is based on Digital Signal Processor (DSP) and Reduced Instruction Set Computer (RISC) hardware. It uses advanced parallel processing techniques in order to achieve the computation speeds required to maintain continuous real-time operation [45].

The RTDS also includes a graphical user interface (GUI) with the RTDS hardware called RSCAD. This software is comprised of several modules designed to allow the user to perform all of the necessary steps to construct, run and analyze simulations cases.

The overall network solution technique used in the RTDS is based on nodal analysis. The underlying solution algorithms are those introduced in [46], which are based on the use of the trapezoidal rule of integration. This solution algorithm is used in virtually all digital simulation programs designed for the study of electromagnetic transients. It is important to mention that for power system simulations, the time-step used is typically on the order of 10 to $50 \mu \mathrm{s}$.

Fig. 16 illustrates a RTDS station, and the RSCAD main window included as GUI of the real-time digital simulator, which runs in any personal computer. It also shows the Rapid Control Prototyping (RCP) scheme [28], where the control strategy for the wind system is implemented through an Arduino due card.

\subsection{Control implementation}

The implementation of controllers was carried-out in an $\mathrm{Ar}$ duino due card through the RCP technique. This development card was selected due to its capability to control the wind system contained in the RTDS platform, where the system is being simulated with a time step of $50 \mu \mathrm{s}$ and the control algorithm is executed in the card with a time step of $20 \mu s$, that is, the Arduino due card is fast enough to host the control algorithms for the test system and can be connected to the RTDS through the GTAI and GTAO cards of 


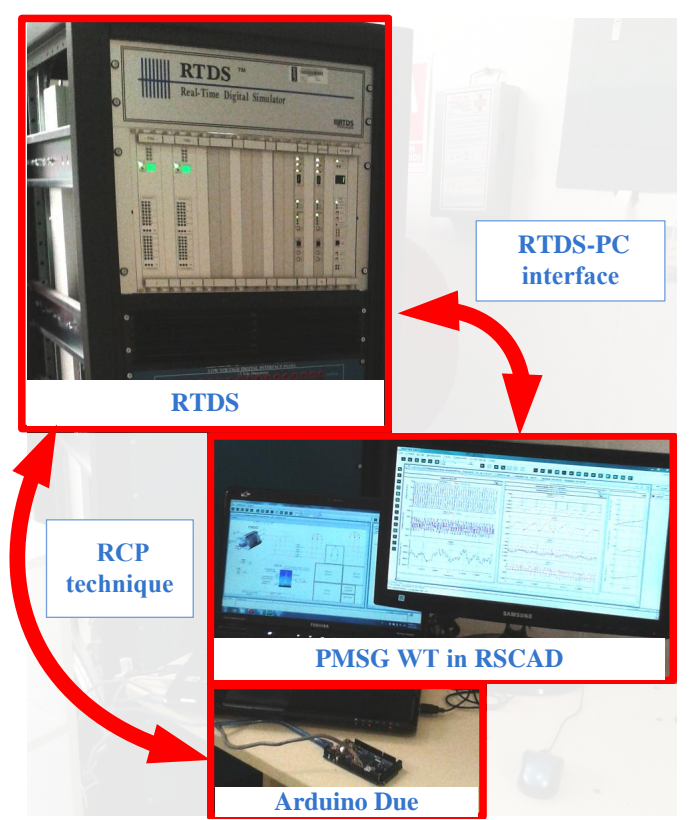

Fig. 16 Real-time implementation setup using RTDS.

the RTDS. The FOC control presented in Section 4.2 was implemented using only one Arduino due card, and the full control strategies were implemented using three Arduino due cards.

In order to implement the law control in a digital platform, difference-equations need to be obtained taking into account the following considerations:

a) The time step considered for mapping the law of control at the $\mathrm{Z}$ domain is $T_{s}=20 \mu \mathrm{s}$, where the Z-transform is [47]:

$$
Z\{G(s)\}=G(z)
$$

b) A typical form of a PI controller in the $\mathrm{Z}$ domain is given by:

$G(z)=\frac{y(z)}{x(z)}=\frac{K_{p z} z-K_{i z}}{z-1}$

c) When the discrete controller is obtained in the form of Eq. (37), it is transformed into a difference-equation and then the inverse Z-transform is applied,

$$
Z^{-1}\left\{\frac{y(z)}{x(z)}\right\}=Z^{-1}\left\{\frac{K_{p z} z-K_{i z}}{z-1}\right\}
$$

d) The difference-equation becomes:

$$
y[k]=y[k-1]+K_{p z} x[k]-K_{i z} x[k-1]
$$

and this equation is programmed in the digital platform.

\subsection{PMSG model implementation}

The PMSG model (Eqs. (7)-(10)) was implemented as a Power system component in the RSCAD software, where it is necessary to take the following considerations:

a) The trapezoidal rule of integration needs to be applied to the equations that describe the behavior of the PMSG wind turbine model. The Eq. (40) has the form necessary in the RTDS solution when the trapezoidal rule of integration is applied to the set of equations,

$i(t)=G_{v a l} v(t)+i(t-\Delta t)$

where $\Delta t$ is the time-step.

b) The inputs, outputs and current injections of the model to the system need to be defined according to the CBUILDER rules.

c) Since the code programmed in the $C$ language is executed in real-time in the RTDS, it is important to write this code as efficiently as possible. For example, avoid divisions if possible, rather than dividing by a constant, compute the inverse of the constant and then multiply by its inverse, since a multiplication is more efficient than a division, etc.

The PMSG wind turbine model developed and implemented in the RTDS is capable of running in real-time, that is, the model runs in less than $50 \mu$ s on each simulation timestep, and it has been successfully connected to other models included in the RSCAD software; the model has the capability of configure their outputs directly in both $a b c$ or $d q$ reference frames, and there are not needed transformation blocks between these two reference frames that make larger the operations on a time-step.

\section{Case studies}

The power system of Fig. 17 is used for the real-time analysis of the PMGS wind turbine under transient operating conditions. This figure also shows the RSCAD representation of the test system. The PMGS wind turbine is connected to a power system through a frequency converter. To this purpose, the detailed model contained in RSCAD of a BTB converter is used. The power system consists of one $\Delta-\mathrm{Y}$ transformer and a double transmission line connected to the power system.

The control system of the PMSG was implemented in an Arduino card through the GTAI and GTAO cards of the RTDS platform with the RCP technique; the PMSG wind turbine and power system are implemented in software and the control strategy is implemented in hardware in order to evaluate its practical performance; its parameters are listed in Appendix A. 


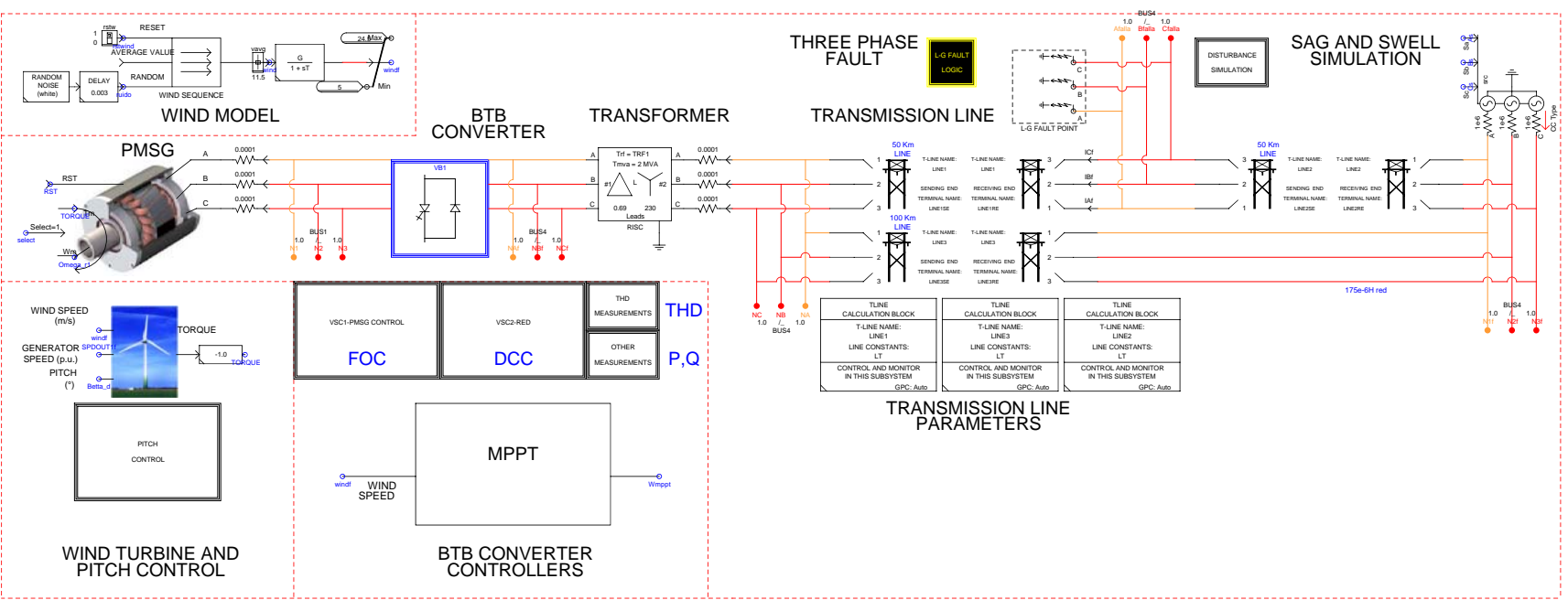

Fig. 17 RSCAD representation of the test system.

7.1 Performance of the controllers with turbulence in the wind

The performance of the controllers can be affected according to the current wind profile. This case study considers a roughness length of $z_{0}=0.01 \mathrm{~m}$ in the wind sequence, which is obtained through simulation with the method presented in the Section 2.1. A $2 \mathrm{MW}$ wind turbine was used.

Fig. 18 shows the operating conditions of the test system in presence of the wind profile with turbulence and the electric variables measured at the PCC. The system must be capable of maintaining the power transmission at different values of the wind.

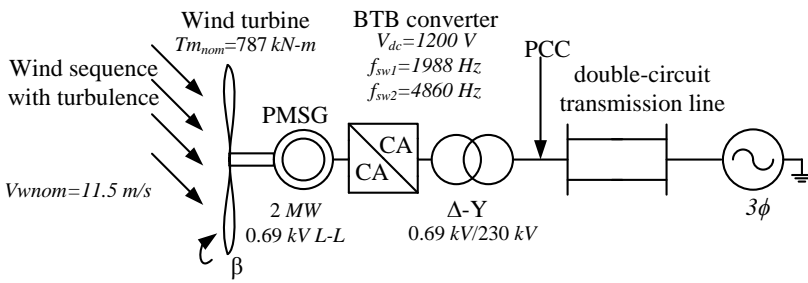

Fig. 18 PMSG wind turbine operation with turbulence in the wind sequence.

Fig. 19 a) shows the wind profile considered for the wind turbine operation. The Fig. 19 b) illustrates the tracking of the mechanical speed to the reference speed given by the MPPT algorithm; it has a good performance in all operating regions. Also in the Fig. 19 c) it can be observed that the pitch angle control works in the HWS region in order to help in the control of the mechanical speed at speeds above to the nominal of the wind turbine.

Fig. 20 shows the electrical power supplied to the grid. In Fig. 20 a), it can be seen the active power in the PCC;
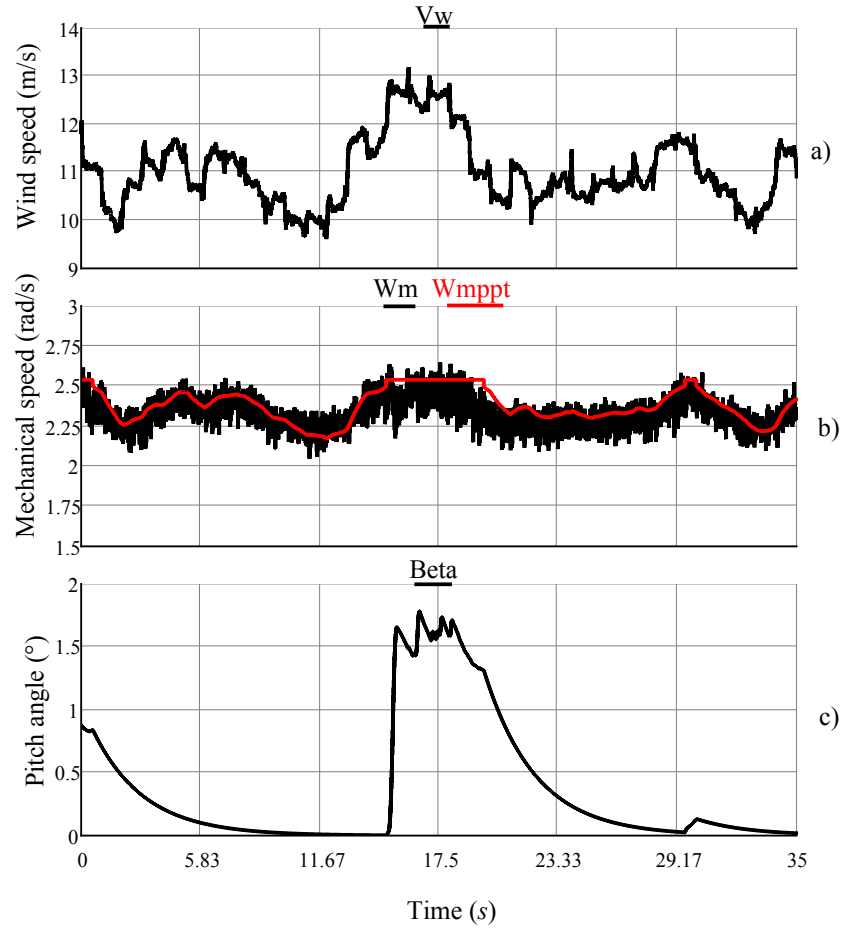

Fig. 19 Performance of the control strategy with turbulence.

while in the Fig. 20 b) the reactive power has a low value to meet a unit power factor; and in Fig. $20 \mathrm{c}$ ) is shown the voltage regulation at the DC-link.

The mechanical system must be protected of an excessive dynamic load, this is achieved by keeping the torque with smooth changes in the switching between operating regions. The results obtained with the proposed control system are shown in Fig. 21, where the torque variations are due to the variable power extracted from the wind, but it does not present large overshoots. 


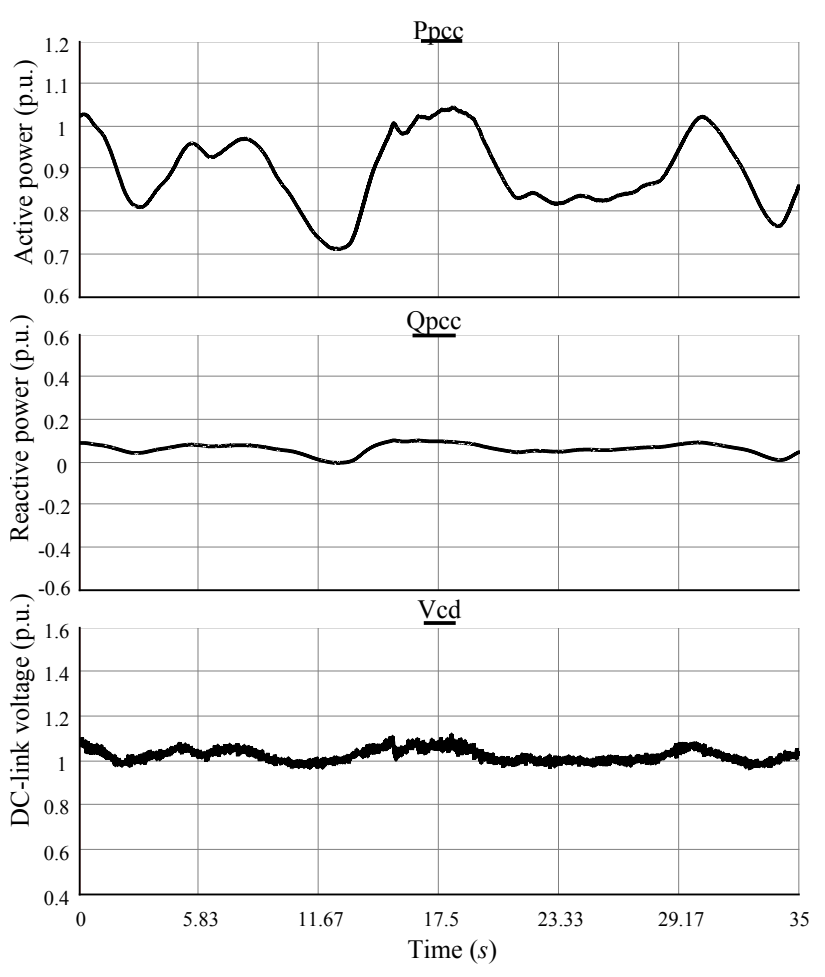

Fig. 20 Output power and DC-link voltage regulation with turbulence.

The results obtained illustrate that the system can send power in different regions of operation according to the changes of wind sequence. The electrical and mechanical variables can be kept within the desired values, that is, a constant value at the DC-link, a value of $P_{p c c}$ according to the wind, $Q_{p c c}$ kept at a low value for a unit power factor and a smooth torque variation.

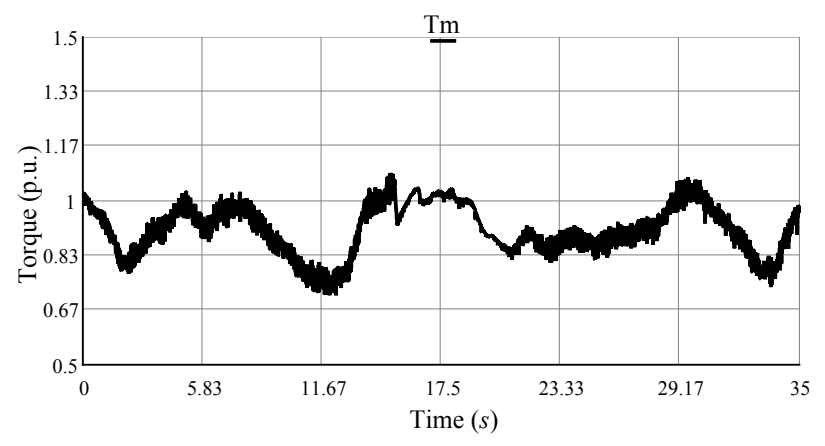

Fig. 21 Mechanic torque obtained in all wind operating regions.

\subsection{Load variations}

In this case study, when the wind system is sending $2 \mathrm{MW}$ of nominal power to the power system, an external load with a value of $1 \mathrm{MW}$ is connected in the test system at 6 seconds of the simulation time. That is a $50 \%$ of the nominal value of the wind turbine; it is removed 15 seconds later. This causes that the power system receives only $1 \mathrm{MW}$ of the $2 \mathrm{MW}$ generated by the wind turbine while the load is connected. a) Fig. 22 shows the scheme used in this case study, where the switch $S_{1}$ allows the insertion and removal of the load.

b)

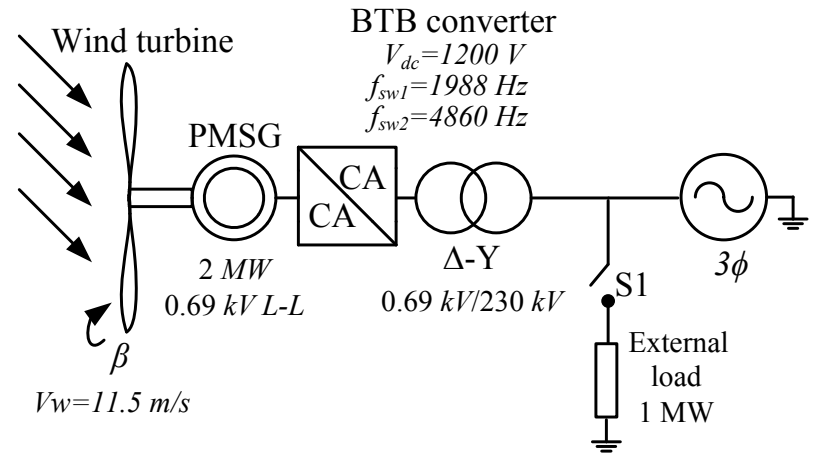

Fig. 22 External load connected to the test system.

Fig. 23 illustrates the behavior of the electrical variables when the load is connected. This simulation was carried-out considering a constant wind speed value of $v_{w}=11.5 \mathrm{~m} / \mathrm{s}$ (see Fig. 23 a)). It can be observed from Fig. 23 b) that the power delivered to the grid is reduced in $50 \%$. Fig. $23 \mathrm{c}$ ) shows that the control system helps to maintain the DC-link voltage in a constant value of $1200 \mathrm{~V}$, and it is not affected by the load change. The Fig. 23 d) shows that the electrical power sent by the wind turbine at the PCC is not affected when this load change occurs.

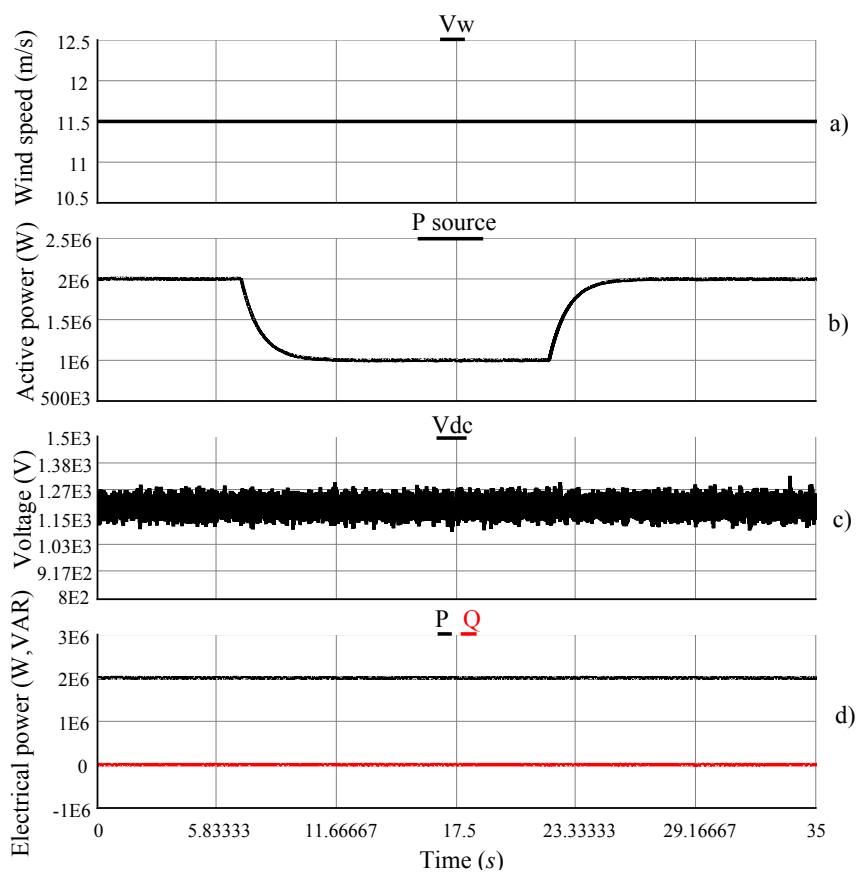

Fig. 23 Behavior of the electrical variables during a change of the load. 
The obtained results for this case study show that the system is capable of return to its steady state after that a load change has been applied.

\subsection{Solid three-phase to ground fault}

This case study tests the Low Voltage Ride-Through (LVRT) capability, which is a requirement for a wind turbine to remain connected to the system without tripping when a shortduration fault occurs in the power system $[48,49]$. Voltage disturbances occur up to specified time periods associated with voltage levels, as described by the grid codes [50] (see Fig. 24). The line of each code indicates that the system must remain in operation if the voltage stays in the zone above the line of the code, according to the time established.

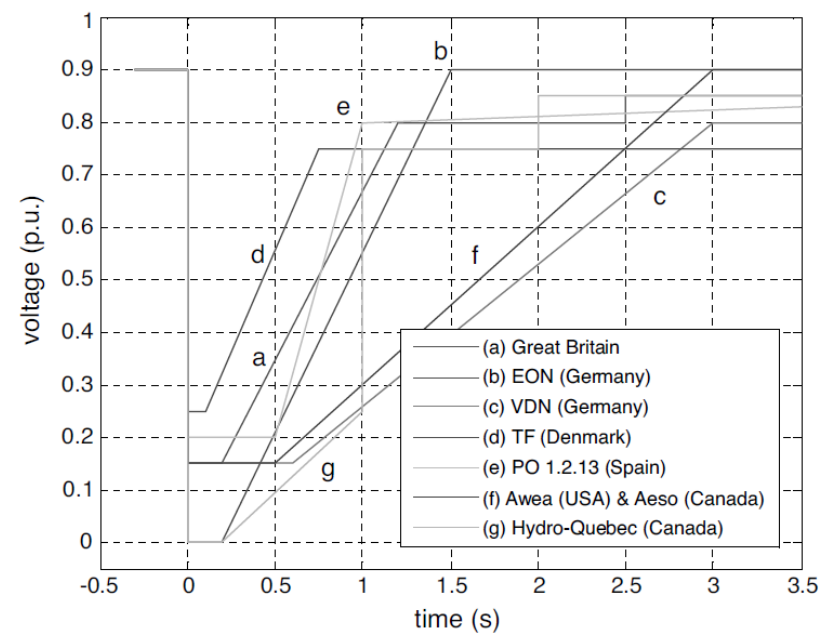

Fig. 24 LVRT requirements for different grid codes [50].

A three-phase fault is applied at the middle of the second transmission system (see Fig. 25), after 6 seconds of simulation time, when the system is already operating in steady state; the fault is maintained for 0.16 seconds and then removed. The voltages and currents at load terminals in the system are presented and analyzed. A solid three-phase fault is applied, as it involves considerable mechanical and electrical stresses.

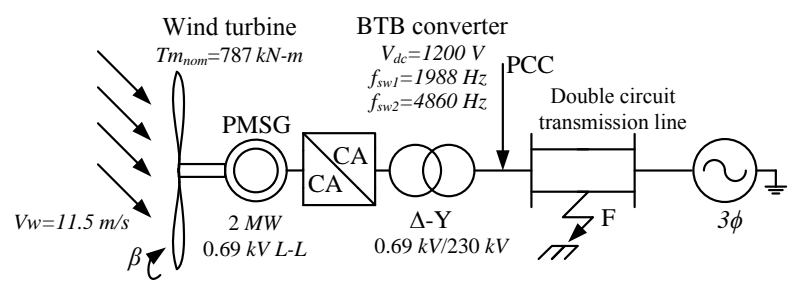

Fig. 25 LVRT capability test system.
In Fig. 26 the behavior of voltages and currents in the presence of the fault is shown. The fault is applied at the middle of the second transmission system at $50 \mathrm{~km}$. After the fault is applied, these currents reach an amplitude of 3.5 p.u., when the fault is removed they return to their pre-fault state.

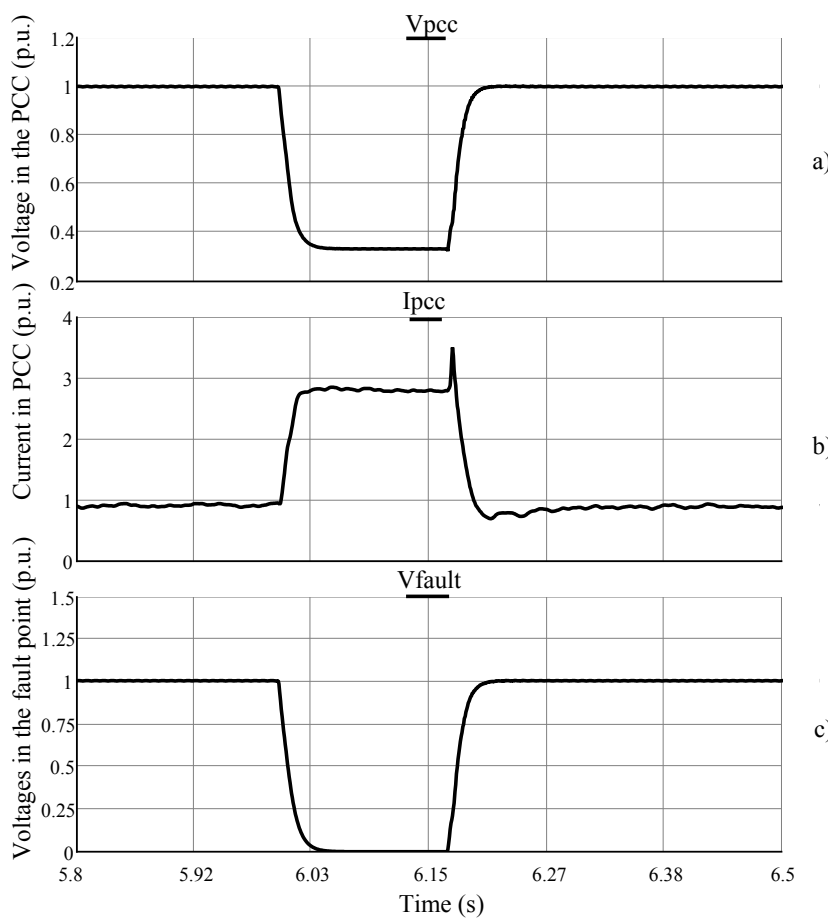

Fig. 26 Behavior of the three-phase voltages and currents in the PCC.

Fig. 27 shows the power exchange at the inverter terminals during the disturbance condition; the PMSG must supply the necessary reactive power to maintain the voltage level at the PCC. This is achieved with the control scheme of the Fig. 28, in which is added a loop of control with a $\mathrm{v}_{\mathrm{pcc}}$ reference.

Fig. 29 shows the behavior of the torque and the mechanical speed. It can be observed that they can go back to their nominal values once the three-phase fault has been removed.

This test shows the LVRT capability of the system when a short-duration fault occurs. Also, it is possible to observe that once the fault is removed the control strategy is capable to help the system to return to its steady state, and to meet the requirements of reactive power for maintain the voltage levels at the PCC, and continue operating with a constant value at the $\mathrm{DC}$-link. 


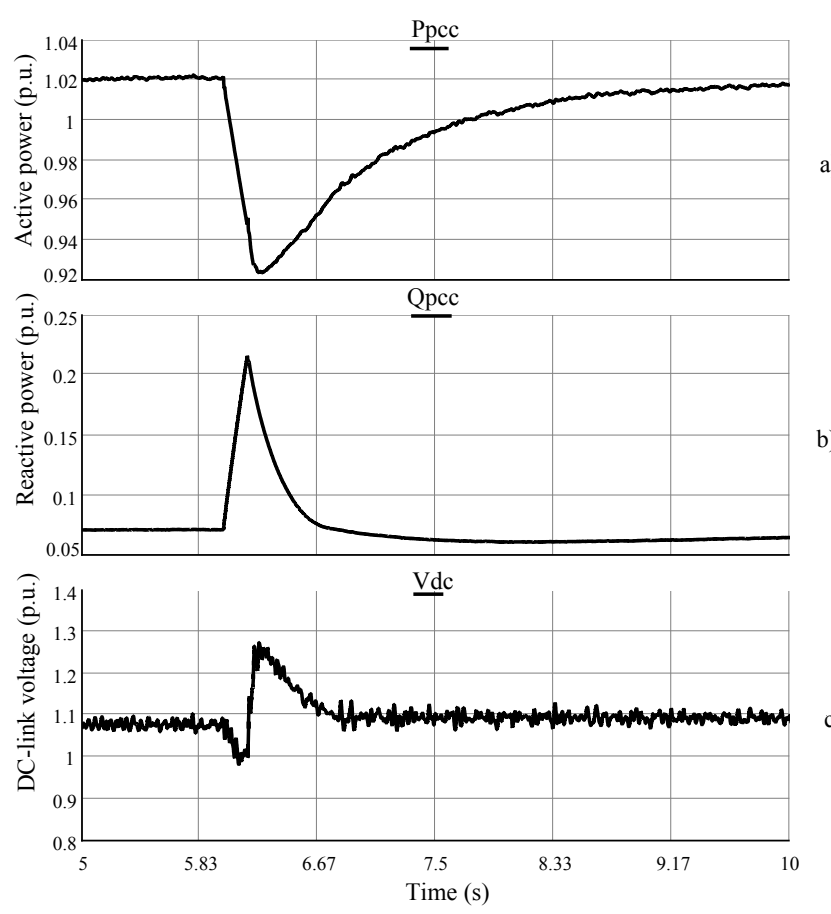

Fig. 27 Behavior of the power exchange in the PCC.

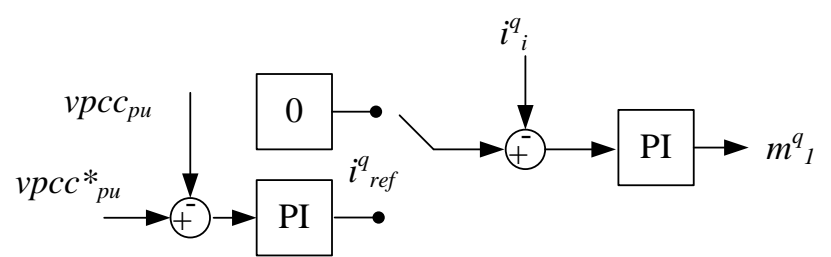

Fig. 28 Change of the reference for $i^{q}$ current when a fault to ground occurs.
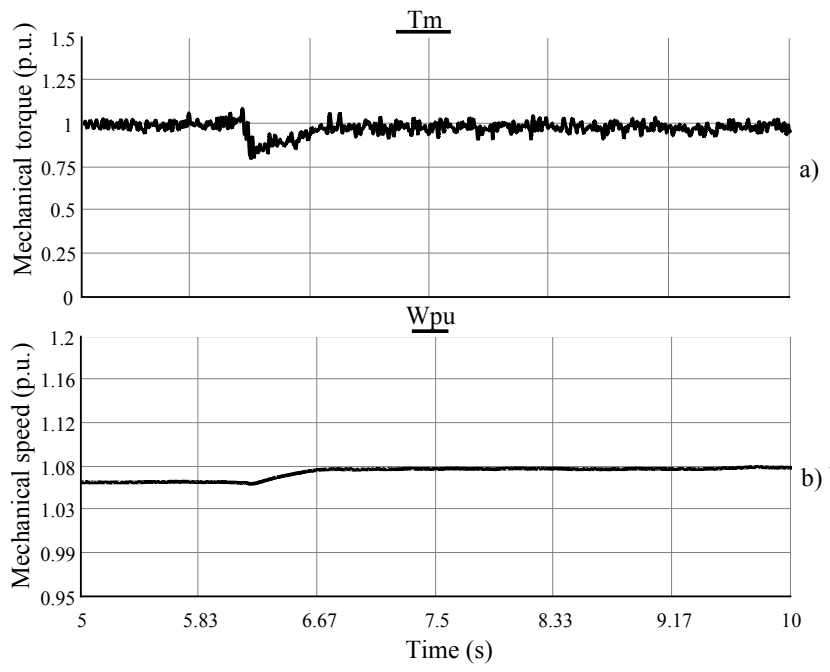

Fig. 29 Behavior of the mechanical variables in presence of a threephase fault.

\section{Conclusions}

In this contribution a full model of a PMSG wind turbine including a BTB converter in the $d q$ reference frame has been proposed and discussed in detail. This model was used for the development of linear control strategies for the wind system. The designed control strategies consider the operation of the variable speed wind turbine within three operating regions, and allow an optimal power extraction from the wind on a wide range of values, with a safe and optimal operation for the power system.

The control strategies have been implemented in Arduino due cards in order to test their behavior under transient conditions. Considerations about their implementation were also presented. By using the developed model and the implemented control strategies, real-time simulations were carriedout.

Three case studies have been presented. The first case shows that the control strategies for the converters can maintain its operation in wide regions of wind, and make possible to extract the optimal power for each wind condition. The second case study evaluates the performance of the wind system when a change of load occurs. It can be observed that the system can go back to its pre-disturbance steady state. Finally, the last case study has shown that the system can keep constant voltage at the PCC when a three-phase fault was applied at the middle of the second transmission system; this according to the grid codes.

\section{Acknowledgments}

The authors want to acknowledge the Universidad Autónoma de San Luis Potosí (UASLP) through the Facultad de Ingeniería, the Facultad de Ingeniería Eléctrica of the Universidad Michoacana de San Nicolás de Hidalgo (UMSNH), and the Institute for Energy and Environment, University of Strathclyde, for the facilities granted to carry-out this investigation.

\section{Appendix A: Parameters of the test system}

The parameters of the test system used in this research are:

Table 1 Parameters of the wind turbine.

\begin{tabular}{lc} 
Wind sequence parameter & Value \\
\hline Shaft height of the wind turbine $h$ & $80 \mathrm{~m}$ \\
Rated wind speed $v_{\omega_{n}}$ & $11.5 \mathrm{~m} / \mathrm{s}$ \\
cut-in wind speed $v_{\min }$ & $5 \mathrm{~m} / \mathrm{s}$ \\
cut-out wind speed $v_{\max }$ & $25 \mathrm{~m} / \mathrm{s}$
\end{tabular}


Table 2 PMSG parameters.

\begin{tabular}{lcc} 
Parameters & Value & Units \\
\hline Nominal power $P_{\text {nom }}$ & 2 & $\mathrm{MW}$ \\
Stator resistance $R_{s}$ & 0.008 & $\Omega$ \\
Leakage inductances in $d q$-frame $L_{d, q}$ & 0.0003 & $\mathrm{H}$ \\
Leakage inductance $L_{l s}$ & 0.00002727 & $\mathrm{H}$ \\
Permanent magnet flux $\lambda_{m}^{\prime r}$ & 3.86 & $\mathrm{wb}$ \\
Number of poles $P$ & 120 & \\
Mechanical speed $\omega_{m}$ & 2.5 & $\mathrm{rad} / \mathrm{s}$ \\
Inertia constant $J$ & 8000 & $\mathrm{~kg} \cdot \mathrm{m}{ }^{2}$ \\
Viscosity coefficient $B_{m}$ & 0.00001349 & $\mathrm{~N} \cdot \mathrm{m} \cdot \mathrm{s}$
\end{tabular}

Table 3 BTB converter and grid parameters.

\begin{tabular}{lcc} 
Parameters & Value & Units \\
\hline Line resistance $R_{1,2}$ & 0.009 & $\Omega$ \\
Line inductance of the generator side $L_{1}$ & 0.0003 & $\mathrm{H}$ \\
Line inductance of the grid side $L_{2}$ & 0.000125 & $\mathrm{H}$ \\
CD-link voltage $v_{d c}$ & 1200 & $\mathrm{~V}$ \\
RMS voltage of the line $v_{1,2}$ & 690 & $\mathrm{~V}$ \\
Inductance of the grid $L_{n}$ & 0.000175 & $\mathrm{H}$ \\
Switching frequency at $\omega_{r_{n o m}}, f_{s w 1}$ & 1988 & $\mathrm{~Hz}$ \\
switching frequency $f_{s w 2}$ & 4860 & $\mathrm{~Hz}$ \\
Frequency index modulation $m_{f 1}$ & 81 & \\
Frequency index modulation $m_{f 2}$ & 81 &
\end{tabular}

Table 4 Transmission line parameters.

\begin{tabular}{lcc} 
Parameters & Value & Units \\
\hline Number of phases & 3 & \\
Positive sequence series resistance & 0.0996228 & $\Omega / \mathrm{km}$ \\
Positive sequence series inductive reactance & 0.514432 & $\Omega / \mathrm{km}$ \\
Positive sequence shunt capacitive reactance & 0.315 & $\mathrm{M} \Omega / \mathrm{km}$ \\
Zero sequence series resistance & 0.3618376 & $\Omega / \mathrm{km}$ \\
Zero sequence series inductive reactance & 1.227747 & $\Omega / \mathrm{km}$ \\
Zero sequence shunt capacitive reactance & 0.34514 & $\Omega / \mathrm{km}$ \\
Length of the line & 100 & $\mathrm{~km}$
\end{tabular}

\section{References}

1. Q. Shi, G. Wang, L. Fu and L. Yuan and H. Huang. State-space averaging model of wind turbine with PMSG and its virtual inertia control. Industrial Electronics Society, IECON 2013 - 39th Annual Conference of the IEEE, Nov. 2013; 1880-1886.

2. M. Martins, A. Perdana, P. Ledesma, E. Agneholm and O. Carlson. Validation of fixed speed wind turbine dynamic models with measured data. Renewable Energy, 2007; 32(8): 1880-1886.

3. Hamid Reza Najafi and Farshad Dastyar. Dynamic maximum available power of fixed-speed wind turbine at islanding operation. International Journal of Electrical Power \& Energy Systems, 2013; 47: 147-156.

4. Deok-Chul Kim, Joon-Ho Choi, Won-Wook Jung, Ju-Yong Kim and II-Keun Song. Modeling and MPPT Control in DFIG-Based Variable-Speed Wind Energy Conversion Systems by Using RTDS. Journal of International Council on Electrical Engineering, 2011; 1(4): 430-436.

5. S.M. Muyeen, Ahmed Al-Durra and J. Tamura. Variable speed wind turbine generator system with current controlled voltage source inverter. Energy Conversion and Management, 2011; 52(7): 2688-2694.

6. H. Shariatpanah, R. Fadaeinedjad and M. Rashidinejad. A New Model for PMSG-Based Wind Turbine With Yaw Control. IEEE Transactions on Energy Conversion, 2013; 28(4): 929-937.
7. Hiskens, I.A. Dynamics of Type-3 Wind Turbine Generator Models. Power Systems, IEEE Transactions on, Feb. 2012; 27(1): 467474.

8. Junfei Chen, Hongbin Wu Sun, Weinan Jiang, Liang Cai and Caiyun Guo. Modeling and simulation of directly driven wind turbine with permanent magnet synchronous generator. IEEE PES Innovative Smart Grid Technologies, May 2012; 1-5.

9. F. Blaabjerg, M. Liserre and K. Ma. Power Electronics Converters for Wind Turbine Systems. IEEE Transactions on Industry Applications, March 2012; 48(2): 708-719.

10. M. Singh, S. Surya. Dynamic models for wind turbines and wind power plants. National Renewable Energy Laboratory, 2011.

11. R. Ben Ali, H. Schulte, and A. Mami. Modeling and simulation of a small wind turbine system based on PMSG generator. 2017 Evolving and Adaptive Intelligent Systems (EAIS), June 2017; 16.

12. E. M. Youness and Z. Othmane. Dynamic modeling and control of a wind turbine with MPPT control connected to the grid by using PMSG. 2017 International Conference on Advanced Technologies for Signal and Image Processing (ATSIP), Oct. 2017; 1-6.

13. G. H. Kim, Y. J. Kim, M. Park, I. K. Yu and B. M. Song. RTDSbased real time simulations of grid-connected wind turbine generator systems. 2010 Twenty-Fifth Annual IEEE Applied Power Electronics Conference and Exposition (APEC), March 2010; 2085-2090.

14. M. Yin, G. Li, M. Zhou and C. Zhao. Modeling of the Wind Turbine with a Permanent Magnet Synchronous Generator for Integration. IEEE Power Engineering Society General Meeting, July 2007; 1-6.

15. A. B. Dehkordi, A. M. Gole and T. L. Maguire. Permanent Magnet Synchronous Machine Model for Real-Time Simulation. International Conference on Power Systems Transients (IPST05), Jun 2005.

16. L. A. Soriano, W. Yu and J. J. Rubio. Modeling and Control of Wind Turbine. Mathematical Problems in Engineering, June 2013; Article ID 982597: 13 pages.

17. W. Liu, L. Chen, J. Ou and S. Cheng. Simulation of PMSG wind turbine system with sensor-less control technology based on model reference adaptive system. Electrical Machines and Systems (ICEMS), 2011 International Conference on, Aug 2011; 1-3.

18. Jemaa Brahmi, Lotfi Krichen and Abderrazak Ouali. A comparative study between three sensorless control strategies for PMSG in wind energy conversion system. Applied Energy, 2009; 86(9): 1565-1573.

19. Ortega, D.F., Shireen, W. and Castelli-Dezza, F. Control for grid connected PMSG Wind turbine with DC link capacitance reduction. Transmission and Distribution Conference and Exposition (T D), 2012 IEEE PES, May 2012; 1-8.

20. B. Malinga. Modeling and control of a wind turbine as a distributed resource. 35th Southeastern Symposium on System Theory, March 2013; 108-112.

21. V. I. Utkin. Sliding Modes in Control and Optimization. Communications and Control Engineering Series, Springer, 1992.

22. B. Beltran, T. Ahmed-Ali, M. E. H. Benbouzid and A. Haddoun. Sliding mode power control of variable speed wind energy conversion systems. IEEE International Electric Machines and Drives Conference (IEMDC '07), May 2007: 943-948.

23. A. S. Yilmaz and Z. zer. Pitch angle control in wind turbines above the rated wind speed by multi-layer perceptron and radial basis function neural networks. Expert Systems with Applications, August 2009; 36(6): 9767-9775.

24. X. Yao, X. Su and L. Tian. Wind turbine control strategy at lower wind velocity based on neural network PID control. International Workshop on Intelligent Systems and Applications (ISA '09), May 2009: 1-5.

25. H. H. Lee, P. Q. Dzung, L. M. Phuong, L. D. Khoa and N. H. Nhan. A new fuzzy logic approach for control system of wind turbine with 
doubly fed induction generator. International Forum on Strategic Technology (IFOST '10), October 2010: 134-139.

26. Y. S. Qudaih, M. Bernard, Y. Mitani and T. H. Mohamed. Model predictive based load frequency control design in the presence of DFIG wind turbine. 2nd International Conference on Electric Power and Energy Conversion Systems (EPECS '11), November 2011: 1-5.

27. Chang Kang, Xue Feng, Fang Yongjie and Yu Yuehai. Comparative simulation of dynamic characteristics of Wind Turbine Doubly-Fed Induction Generator based on RTDS and MATLAB. Power System Technology (POWERCON), 2010 International Conference on, Oct 2010; 1-8.

28. M. Tursini, L. Di Leonardo, C. Olivieri and E. D. Loggia. Rapid Control Prototyping of IPM Drives by Real Time Simulation. 2013 8th EUROSIM Congress on Modelling and Simulation, Sept 2013; 364-371.

29. T. Yao, I. Leonard, R. Ayyanar and M. Steurer. Single-phase threestage SST modeling using RTDS for controller hardware-in-theloop application. 2015 IEEE Energy Conversion Congress and Exposition (ECCE), Sept 2015; 2302-2309.

30. R. Peña and A. Medina. Real time simulation of a power system including renewable energy sources North American Power Symposium (NAPS), Sept 2012; 1-5.

31. Ming Yin, Gengyin Li, Ming Zhou and Chengyong Zhao. Modeling of the Wind Turbine with a Permanent Magnet Synchronous Generator for Integration. Power Engineering Society General Meeting. IEEE, Jun 2007; 1-6.

32. Robert J. Howlett, Nacer Kouider M'Sirdi, Aziz Naamane, Ali Sayigh, Y. Errami, M. Ouassaid and M. Maaroufi. Control of a PMSG based Wind Energy Generation System for Power Maximization and Grid Fault Conditions. Mediterranean Green Energy Forum 2013: Proceedings of an International Conference MGEF13, Energy Procedia, 2013; 42: 220-229.

33. T. Ackermann. Wind Power in Power Systems. Wiley,2005.

34. González-Longatt, FM., Amaya, O., Cooz, M., Duran, L., Peraza, C., Arteaga, FJ. and Villanueva C. Modelación y simulación de la velocidad de viento por medio de una formulación estocástica. Revista INGENIERÍA UC, Dec 2007; 14(3): 7-15.

35. Wai, R.-J., Lin, C.Y. and Chang, Y.R. Novel maximum-powerextraction algorithm for PMSG wind generation system. Electric Power Applications, IET, March 2007 1(2): 275-283.

36. Quincy Wang and Liuchen Chang. An intelligent maximum power extraction algorithm for inverter-based variable speed wind turbine systems. Power Electronics, IEEE Transactions on, Sept 2004; 19(5): 1242-1249.

37. Siegfried Heier. Grid Integration of Wind Energy Conversion Systems. Wiley, 1998.

38. Krause, P.C. and Wasynczuk, O. and Sudhoff, S.D. and Pekarek, S. Analysis of Electric Machinery and Drive Systems. IEEE Press Series on Power Engineering, 2013.

39. Rafael Peña, Aurelio Medina and Olimpo Anaya-Lara. Steadystate Solution of Fixed-speed Wind Turbines Following Fault Conditions Through Extrapolation to the Limit Cycle. IETE Journal of Research, Jan 2011; 57(1): 12-19.

40. Alcala, J., Cardenas, V., Ramirez-Lopez, A.R. and Gudino-Lau, J. Study of the bidirectional power flow in Back - to - Back converters by using linear and nonlinear control strategies. Energy Conversion Congress and Exposition (ECCE), 2011 IEEE, Sept 2011; 806-813.

41. J. Segundo and A. Medina. Modeling of FACTS Devices Based on SPWM VSCs. IEEE Transactions on Power Delivery, Oct 2009; 24(4): 1815-1823.

42. Bianchi, F.D., De Battista, H. and Mantz, R.J. Wind Turbine Control Systems, principles, modelling and gain scheduling design. Advances in Industrial Control series, Springer, 2007.

43. A. Tobías, R. Peña, J. Morales and G. Gutierrez. Modeling of a wind turbine with a permanent magnet synchronous generator for real time simulations. 2015 IEEE International Autumn Meeting on Power, Electronics and Computing (ROPEC), Nov 2015; 1-6.

44. Van der Broeck, H.W., Skudelny, H.-C. and Stanke, G.V. Analysis and realization of a pulsewidth modulator based on voltage space vectors. Industry Applications, IEEE Transactions on, Jan 1988; 24(1): 142-150.

45. RTDS technologies. Real Time Digital Simulator Tutorial Manual. Winnipeg Canadá 2015.

46. Dommel, H.W. Digital Computer Solution of Electromagnetic Transients in Single-and Multiphase Networks. Power Apparatus and Systems, IEEE Transactions on, Apr 1969; 88(4): 388-399.

47. Phillips, C.L. and Nagle, H.T. Digital control system analysis and design. Prentice-Hall, 1984.

48. H. Ali Mohd. Wind energy systems, solutions for power quality and stabilization. CRC Press, 2012.

49. V. Pagola, R. Peña and J. Segundo. Low voltage ride-through analysis in real time of a PV-Wind hybrid system. 2015 IEEE International Autumn Meeting on Power, Electronics and Computing (ROPEC), Nov 2015; 1-6.

50. Abad, G., López, J., Rodríguez, M., Marroyo, L. and Iwanski, G. Doubly Fed Induction Machine: Modeling and Control for Wind Energy Generation. IEEE Press Series on Power Engineering, Wiley 2011. 